\title{
BASE CALCULATION OF ANCHOR FOUNDATIONS USING APPROXIMATE MODEL TESTING
}

\section{Calcul des fondations d'ancrage à l'aide des modèles approximatifs}

\author{
by
}

\author{
A.S. KANANYAN, \\ Research Institute of Foundations and Underground Structures, Gosstroy URSS \\ M.I. NIKITENKO, YU.A. SOBOLEVSKY, V.N. SUKHODOEV \\ Byelorussian Polytecnic Institute
}

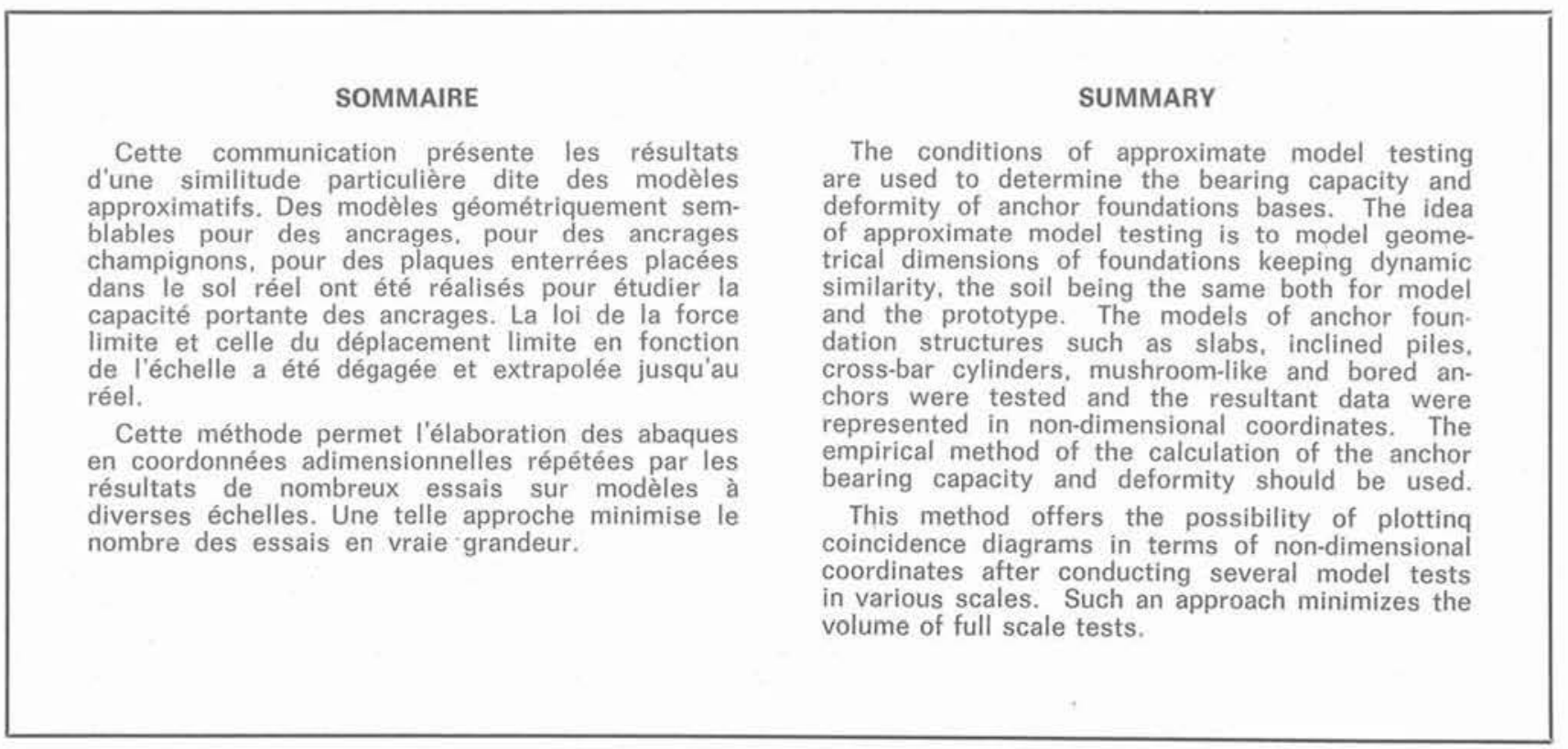

It is rather difficult to make analytical calculations of bearing capacities and deformations of anchor foundation bases, owing to the absence of axial symmetry and non-linear deformations.

That is why it is advisable to use an approximate modeling in order to determine the bearing capacity and anchor foundation deformity. In the $50 \mathrm{~s}$ the by D.E. Polshin. According to the concept, geometrical dimensions of the foundation were modelled with the dynamic similarity kept, and the soils the same both for the model and the prototype [1].

The systemizing of test results is done in nondimensional coordinates which gives the opportunity to minimize and sometimes to eliminate the effect of the model on the final results determining the bearing capacity and natural foundation base deformation [2], [3], [4].

The models of the anchor foundation parts such as slabs, inclined piles, cross-bar cylinders, mushroomlike and bored anchors were tested and the resultant data were represented in non-dimensional coordinates $[5],[6],[7],[8]$. The methods of each model loading were taken to be equal according to the requirements of the kinematic and dynamic similarity. The anchors were subjected to pulling force step by step and were kept till stabilization of displacement in the point of load application was achieved.
During every model test no less than 10 experimental values for the diagram «load-displacement» were obtained as the steps of loading were nearly $1 / 10$ of their maximum value. The tests were considered finished when either a sudden loss in bearing capacity with soil deformation or increasing displacement took place without additional loading.

The last loading step when the anchor displacement stabilization set in was taken as a maximum $\mathrm{N}_{\text {lim }}$, while the displacement $\mathrm{U}_{\text {lim }}$ corresponded to this loading. The loading $\mathrm{N}_{\mathrm{lim}}$ was prior to the maximum value of pulling force.

The test results of different anchor foundation structures in sand and clay soils indicated that the dependence «load-displacement» is non-linear as the compaction and displacement deformation of base soil takes place simultaneously, one of the types predominating at the beginning and at the end of loading.

The «load-displacement" curves for different models and prototypes have in absolute values quite a different character, without giving the opportunity to generalize the dependence function for the "base-foundation" system. The diagram of the above dependencies in absolute values by test data does not provide their true significance even qualitatively. Thus, for instance, diagram curvature depends on the choice of scales of displacement and loading values. The natural dispersing of deformation experimental values for this or that 
load in repeated tests influences the diagram curvature as well. The estimation of such diagrams, taking into account the variety of soil conditions, becomes more difficult for foundation models and prototypes of various constructions and dimensions.

When the diagram of "load-displacement" dependence is compiled in relative values, we have quite another picture. The ratio of acting loads $\mathrm{N}_{i}$ to their maximum value $\mathrm{N}_{\text {ult }}$ marked on the abscissa axis in the unique system of non-dimensional coordinates and the corresponding relations between $\mathrm{U}_{i}$ and $\mathrm{U}_{\lim }$ displacements are marked on the ordinate axis. Such a systemizing of test results makes it possible to compare the dependences for anchor foundations of different scale and to get equations of relative parameter connections.

$$
\frac{\mathrm{U}_{i}}{\mathrm{U}_{\lim }}=f \frac{\mathrm{N}_{i}}{\mathrm{~N}_{\mathrm{lim}}} \text { or } \mathrm{C}_{i}^{u}=f\left(\mathrm{C}_{i}^{\mathrm{s}}\right)
$$

The tests diagrams in non-dimensional coordinate were plotted in accordance with the anchor foundation structures in the scale range from 1: 10 to 1 : 1 according to the tests in sand and clay soils (fig. 1, 2) The analysis of the diagrams showed their characteristics as follows:

1. The diagrams are characterized by convexity which shows the non-linear nature of anchor foundation base deformation and the growth of displacements during the next steps of load application.

2. The vague diagram curvature shows the foundation properties: the abrupt curve corresponds to shallow anchor foundations, soft soils having low mechanical characteristics; the flat curving corresponds to deeper foundation bedding and compact soils with much better mechanical characteristics.

3. The diagrams remain just the same for anchor foundation models both over the whole scale range and in a part of the range and this opens wide opportunities for extrapolation of test results.

4. The diagram curvature is not affected by the dimensions and the shape of foundations as well as the angle of pull-out, though these parameters influence the absolute values of maximum displacements and efforts.

5. The comparison of test results of pulling out rammed piles and cylindrical anchors put into leading wells shows that the curvature of «load-displacement» non-dimensional diagram is more abrupt in the first case than in the second one.

The accuracy of base calculations under approximate model testing conditions depends greatly on the definition of the foundation displacement maximum values. It is reasonable therefore to lessen the loading steps before foundation bearing capacity limit is achieved.
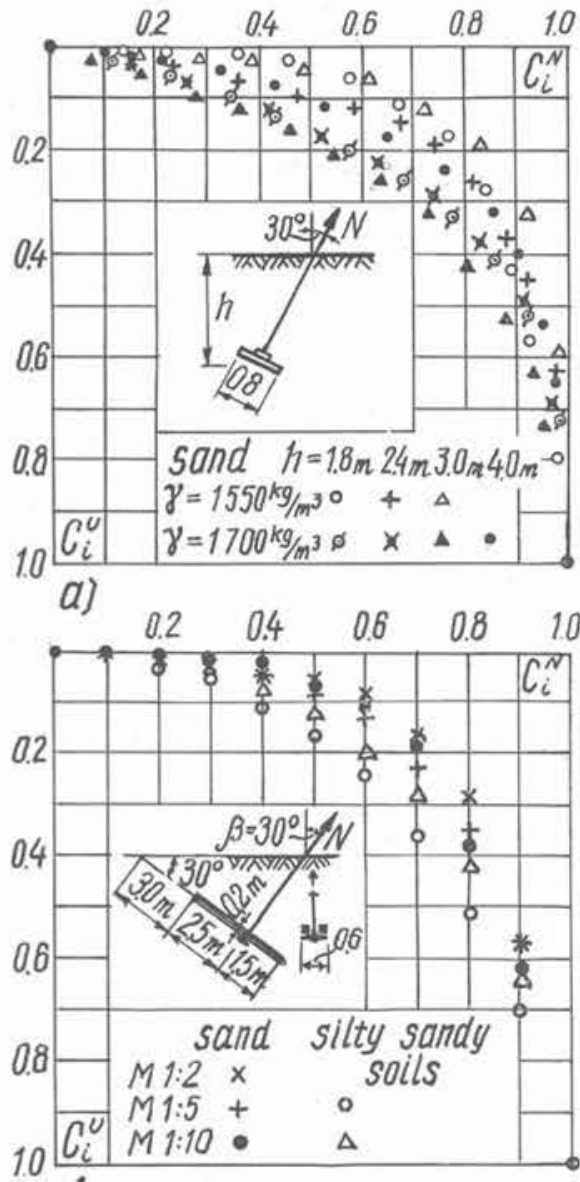
d)
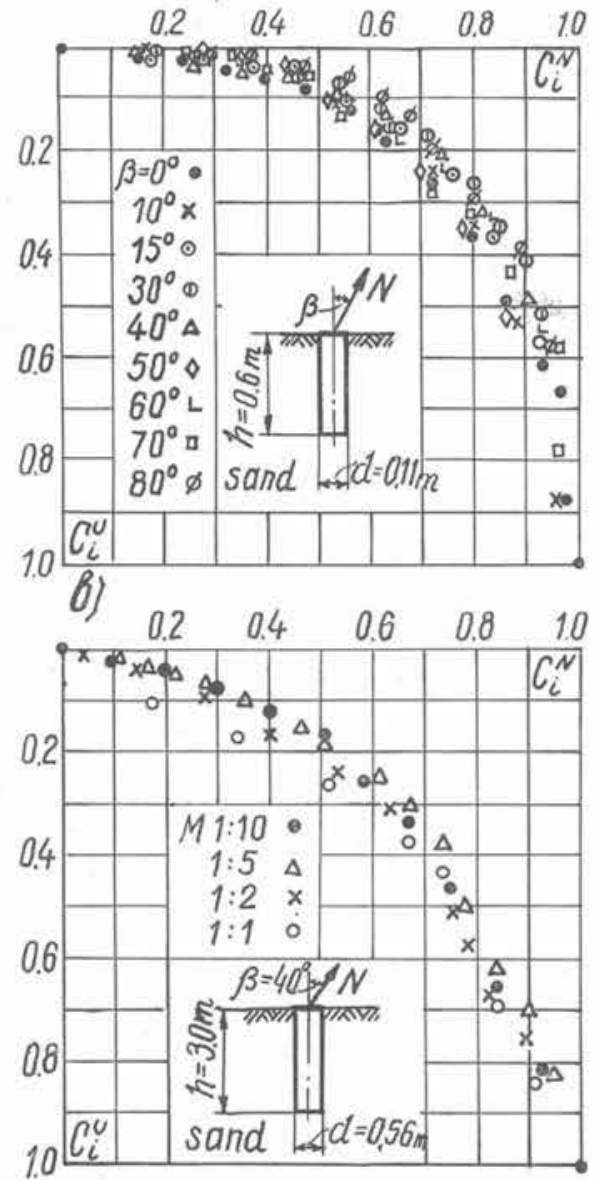

e)
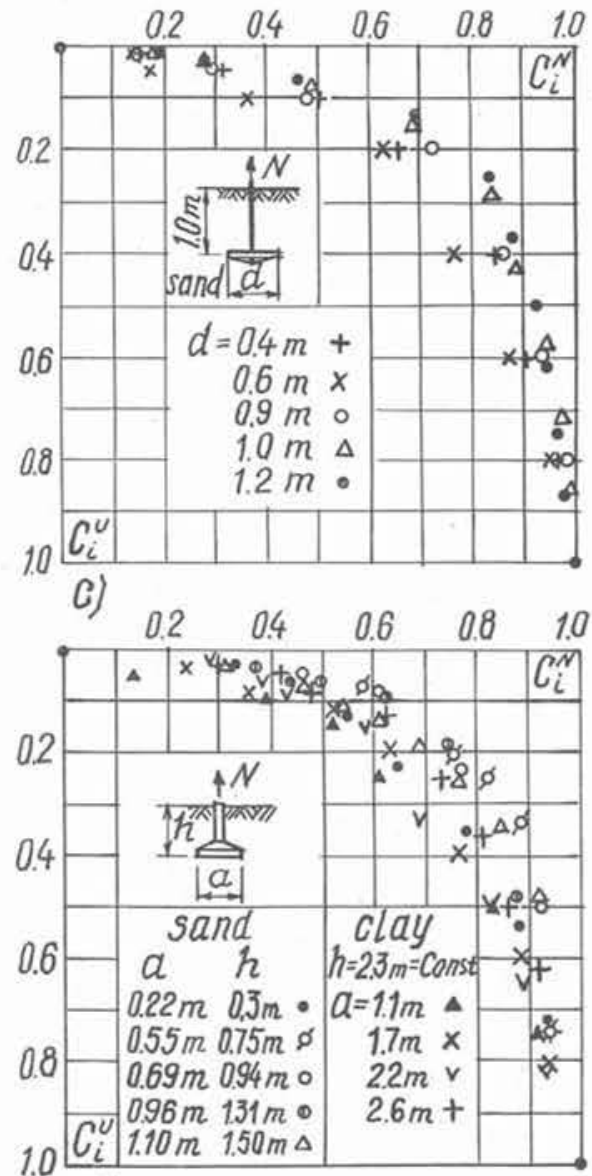

f)

Fig. 1. - Average eload-displacement» dependence in approximate values for anchor foundations a) right-angled inclined slabs with $80 \times 500 \mathrm{~mm}$ in average-sized sand; b) cross-bar cylinders when being piled into the average-sized sand; c) round slabs in sand of average size and density; d) inclined piles in fine sand of average density and in hard dusty sandy loam; e) cross-bar cylinders when using the principle method of boring into the sand of average size and density; f) mushroomlike foundations in sand of average size and density and in a hard clay. 


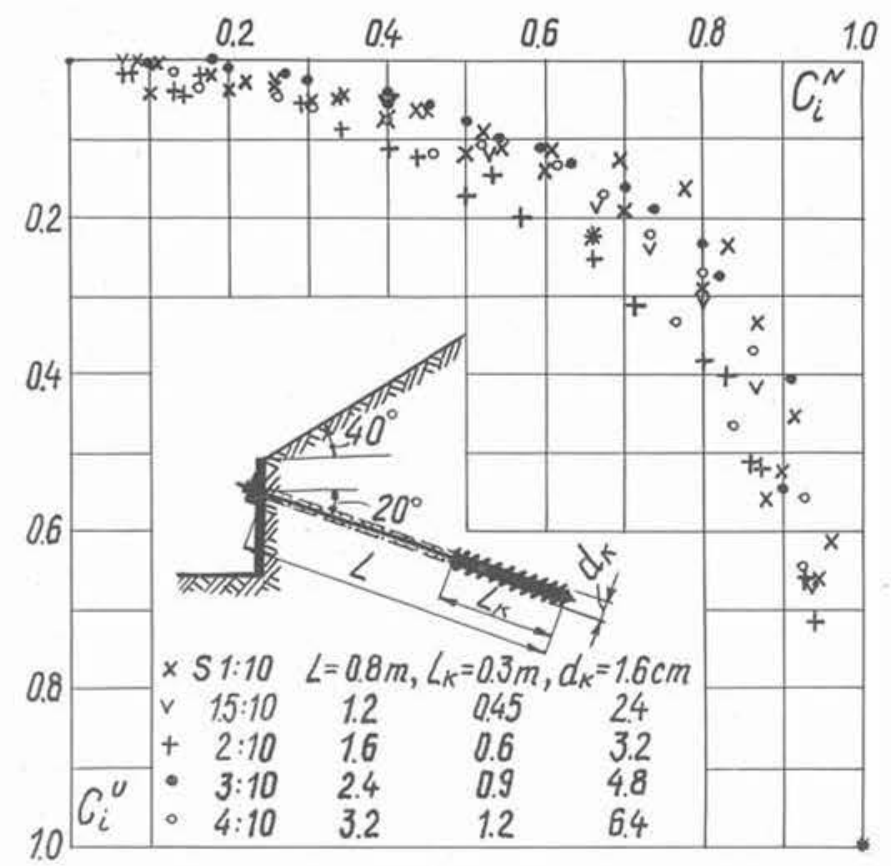

Fig. 2 - Average aload-displacement» dependences in approximate values for inclined anchors in soft sandy morainic loam.
As the summarizing of available data shows, one must be sure that the test is conducted properly in order to minimize the dispersing of results, i.e to see if all the adopted methods of model testing and the accuracy of effort and displacement measurements are observed carefully till the limit of foundation bearing capacity is achieved. The soil for model testing must have similar physical and mechanical characteristics. Fig. 3, 4, 5, 6, show diagrams of maximum values of stabilized pulling forces $\mathrm{N}_{\text {lim }}$ and the corresponding displacements $\mathrm{U}_{\mathrm{lim}}$ depending on anchor model scale.

Dependence $\mathrm{N}_{\text {lim }}=f(\mathrm{~S})$ is curved and has power function character, but the dependence $\mathrm{U}_{\lim }=f(\mathrm{~S})$ is almost linear, which simplifies the extrapolation of the foundation model test results.

This almost linear character of the dependence of maximum stabilized displacement followed by pulling out the anchors will remain the same even for larger prototypes. Such a conclusion is based on the thought that anchor soil base lies above the footing. "Loadscale» dependences are also convenient to represent in a unique system of non-dimensional coordinates for all the anchor foundation structures. The scale ratios or ratios of linear dimensions of prototypes and models are marked on the abscissa axis and corresponding ratios of their maximum loads are marked on the ordinate axis. Any foundation scale, natural dimensions included, can be taken as a single one in tis coordinate system, other scales being prototypes.
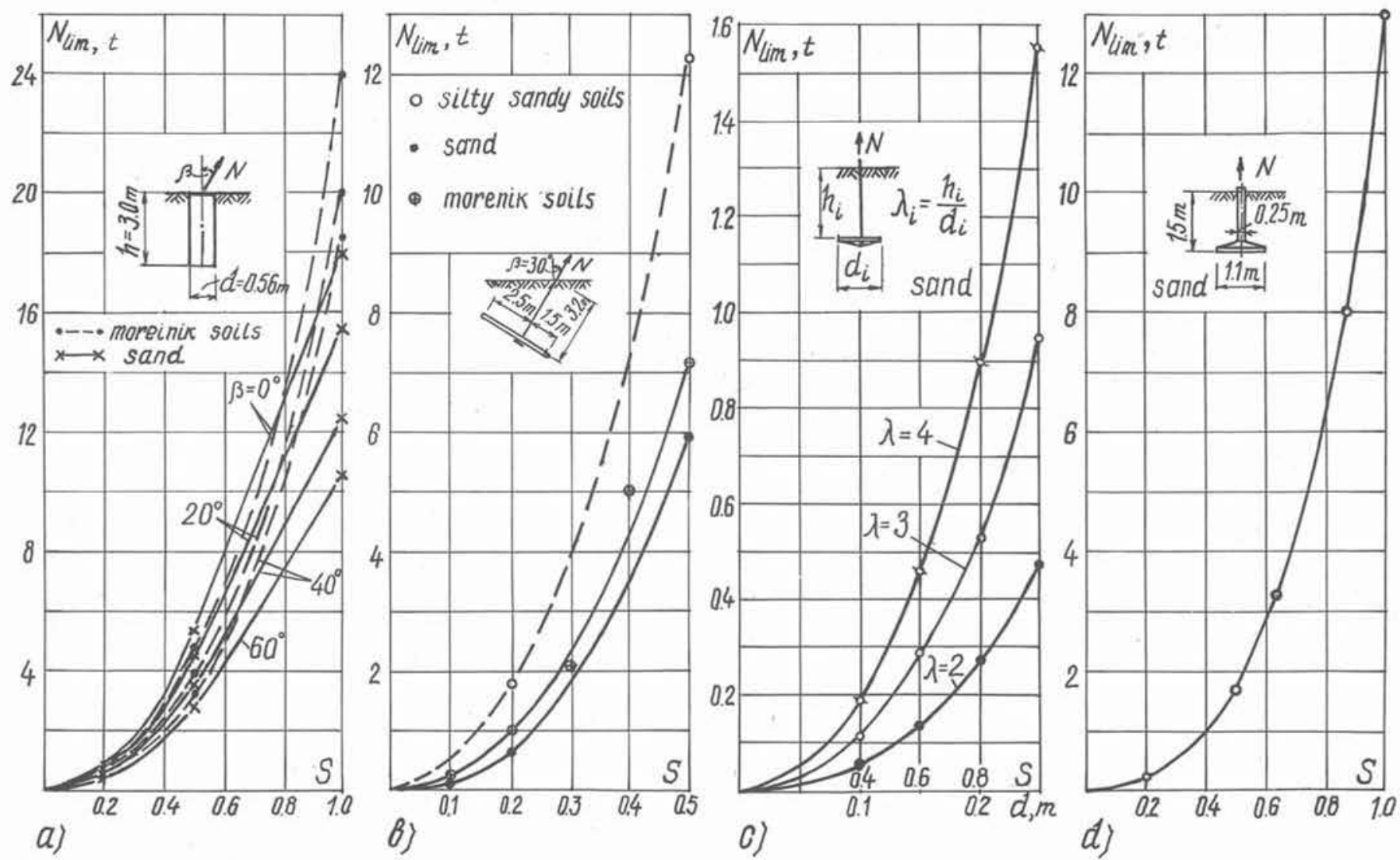

Fig. 3. - Average «model-scale-load» dependences for anchor foundations: a) cross-bar cylinders in sand and in the morainic sandy loam; b) inclined paired piles in sand and in dusty sandy loam, single piles in morainic sandy loam; c) round slabs in sand; d) mushroom-like foundations in sand. 


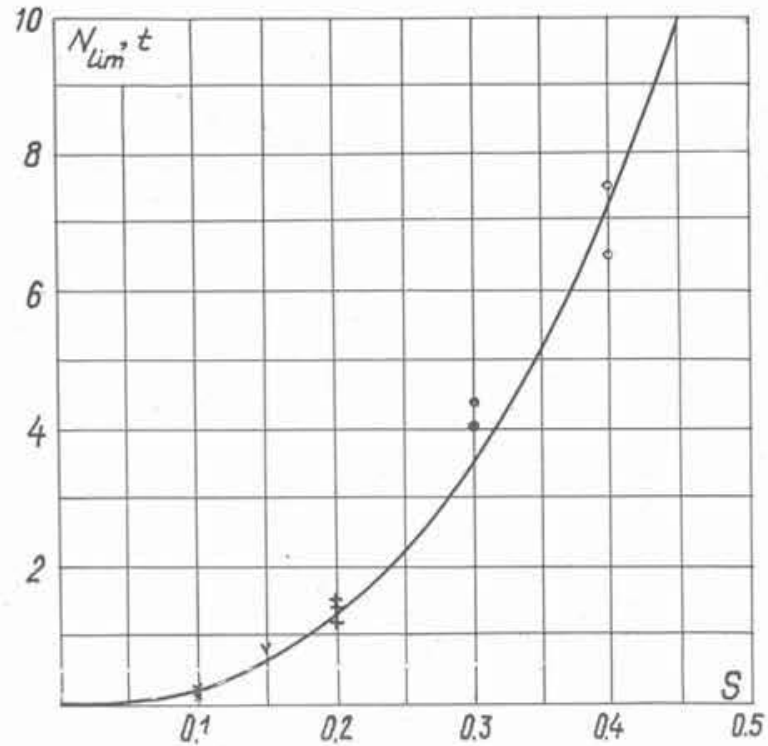

Fig. 4. - "Model scale-maximum displacement" for sloped boring anchors in soft sandy morainic loam.

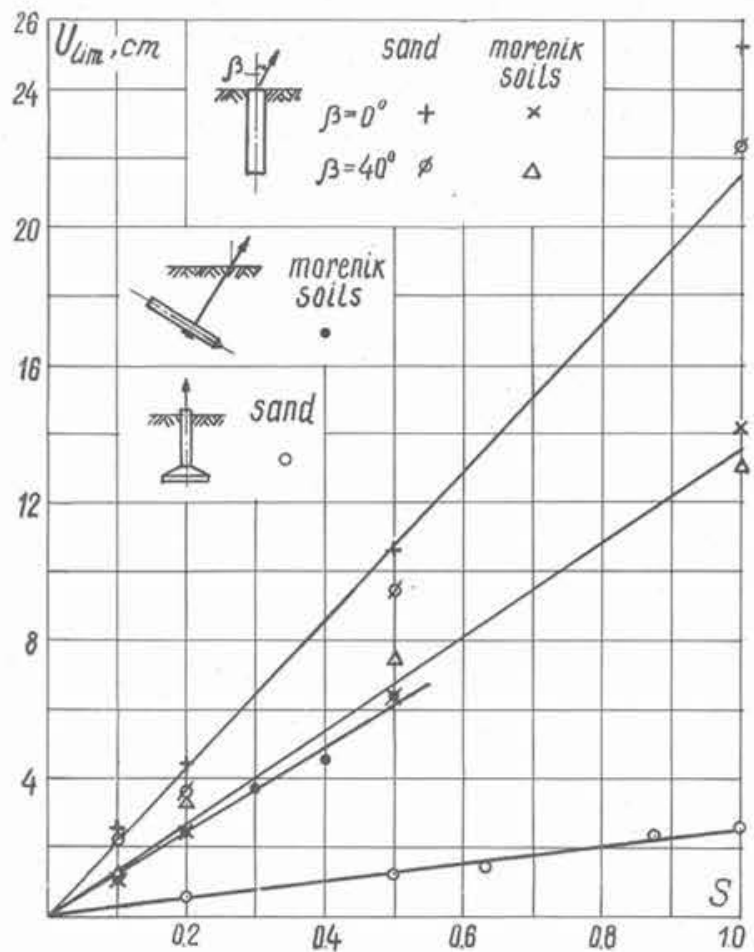

Fig. 5. - Average "model scale-maximum displacement» dependences for anchor foundations. 1) cross-bar cylinders in sand; 2) cross-bar cylinders in morainic sandy loam; 3) inclined single piles in morainic sandy loam; 4) mush. room-like foundations in sand.

Dependences $\frac{N_{N}^{\text {prot }}}{N_{\text {lim }}^{\text {prot }}}=f\left(C_{L}\right)$ are represented in fig. 7, 8.

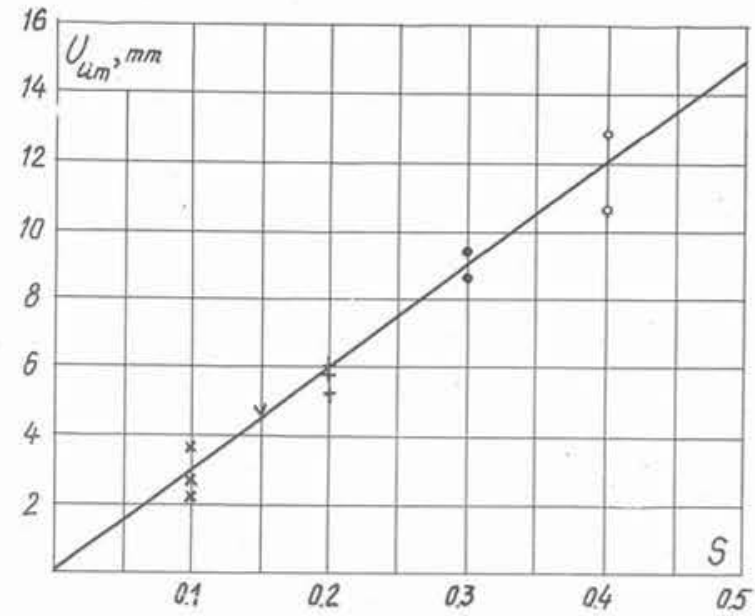

Fig, 6. - ${ }^{-}$Model scale-maximum displacement ${ }^{\prime}$ for inclined bored anchors in soft sandy morainic loam.

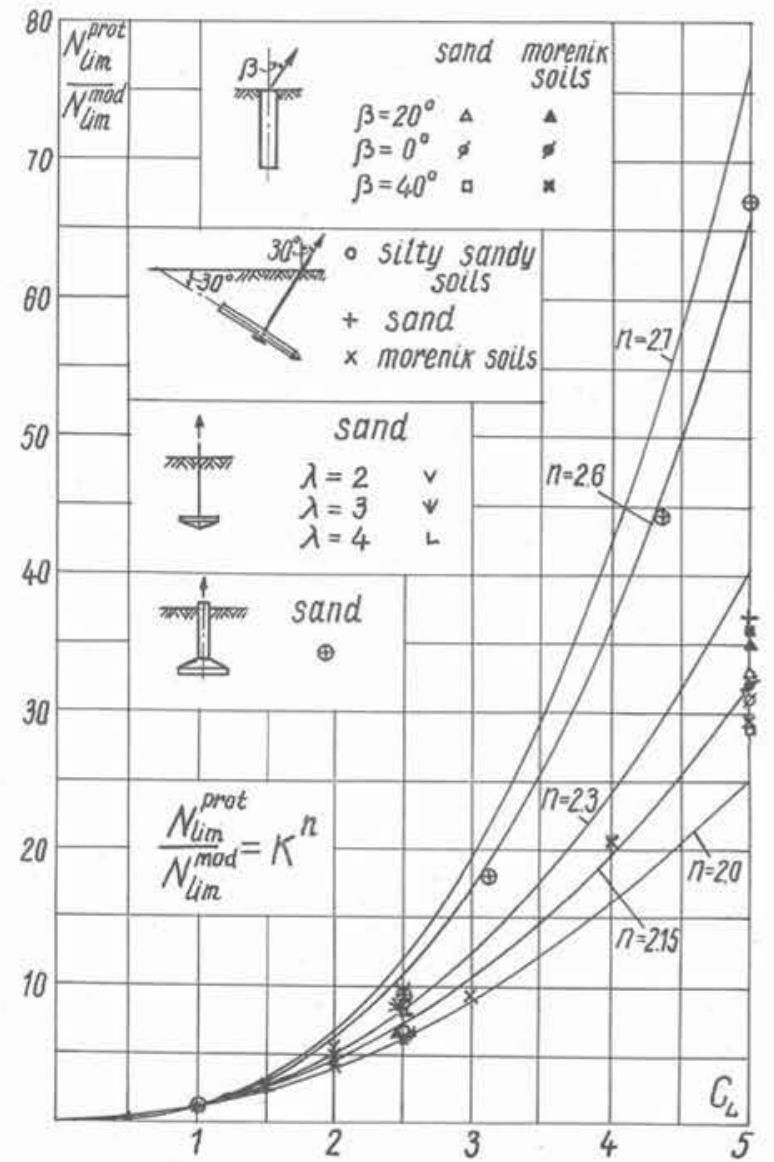

Fig, 7. - Average «model scale-loadn dependences calculated in approximate values for anchor foundations of different constructions (curved diagrams are compiled according to the equation 2 with $n$ having different values). 


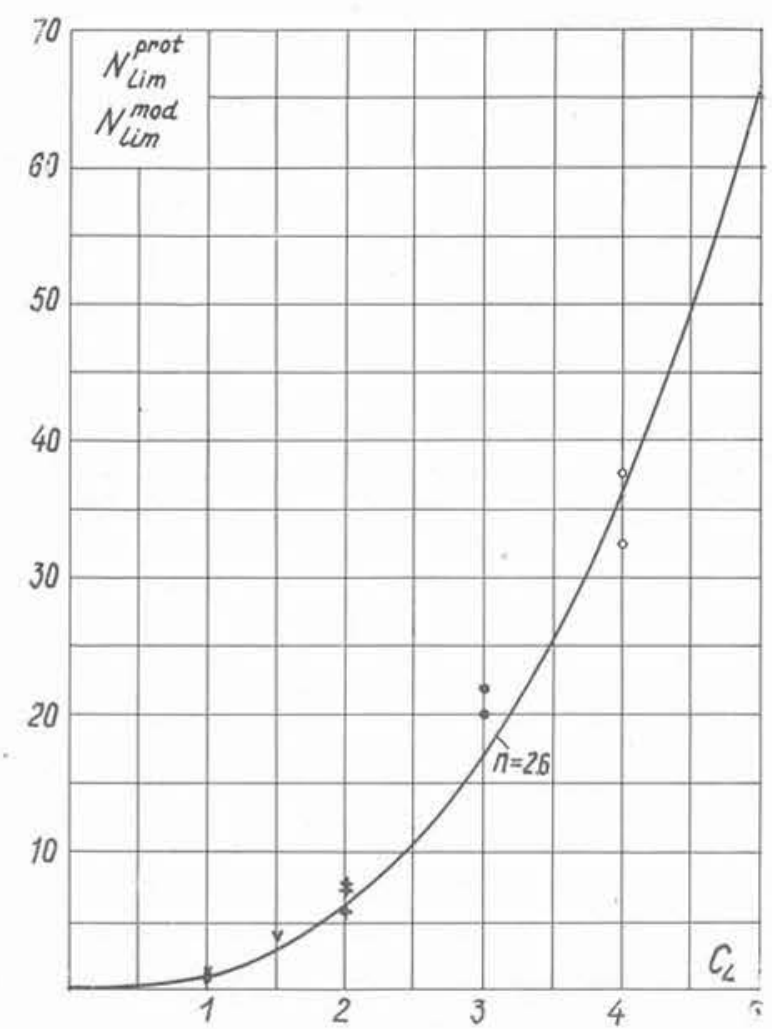

Fig. 8. - "Model scale-loading" dependences in approximate values for inclined bored anchors (curved diagram is compiled according to the equation 2 where $n=2.6$ ).

Systemizing the obtained results it is possible to approximate them in the following expressions:

$$
\frac{\mathrm{N}_{\mathrm{lim}}^{\text {prot }}}{\mathrm{N}_{\mathrm{lim}}^{\text {mod }}}=\mathrm{C}_{\mathrm{L}}^{n}
$$

$$
\frac{\mathrm{U}_{\mathrm{lim}}^{\text {prot }}}{\mathrm{U}_{\mathrm{lim}}^{\text {mod }}}=\mathrm{C}_{\mathrm{L}}
$$

where $C_{L}$ is the ratio of linear dimensions or prototype and model scales; $n$ is the coefficient depending on anchor foundation construction and the kind of soil. Its values for anchor foundation models in sand and clay soils are found to be in the interval from 2 to 2.7. It is possible to take $n=2.15$ for cylindrical and inclined piled anchors, $n=2.3$ for anchor slabs and $n=2.6$ for mushroom-like foundations with some stability of foundation in the first approximation.

Thus, using the principle of approximate similarity, with summarizing the model tests of anchor foundation structures in relative values, makes it possible to introduce the empirical method of calculations of natural foundation bearing capacity and deformity. The essence of this method can be represented in the following way.

Repeated ( 3 or 5 times) model tests of anchor foundation of definite construction in corresponding soil conditions are carried out and approximate model testing requirements are observed, the limit of foundation bearing capacity being exhausted by pull-out.

The values

$$
\mathrm{N}_{\mathrm{lim}}^{\bmod } \text { and } \mathrm{U}_{\mathrm{lim}}^{\mathrm{mod}}
$$

are determined. Multiplying model test results by transitional coefficients according to dependencies (2) and (3), the ultimate points of prototype displacement and loading are found in absolute values. Afterwards they are multiplied by non-dimensional coordinates of intermediate points of the "load-displacement" dependence and a diagram is plotted for natural foundation. The diagram gives the opportunity to find corresponding efforts or displacements caused by them with the necessary reliability. The calculated load is determined by means of permissible displacements.

The principle of the calculation of anchor foundation bases with the use of small-scale models test results will be shown in the following example.

\section{CALCULATION EXAMPLE}

It is necessary to calculate the displacement and stability of the model of the inclined bored anchor foundation having the following dimensions: full length
$3.2 \mathrm{~m}$, the root $6.4 \mathrm{~m}$ in diameter and $1.2 \mathrm{~m}$ in length, the inclination of the axis $-20^{\circ}$, the slope angle of the boring depth $-40^{\circ}$ ) in morainic sandy loam.

\section{SOLUTION}

1. Average «load-displacement» dependences were obtained for the model which is 4 times less than the anchor being calculated and having equal deflection from horizon and the slope angle depth; tests were repeated three times in identical soil. The nondimensional parameters are given in table I.
The arithmetical mean values $\mathrm{N}_{\mathrm{lim}}^{\mathrm{mod}}$ and $\mathrm{U}_{\mathrm{lim}}^{\mathrm{mod}}$ according to the test results were $0.20 \mathrm{t}$ and $0.30 \mathrm{~mm}$ respectively.

2. The maximum value of the base bearing capacity of calculated bored anchor and its displacement are determined in the following way.

TABLE 1

\begin{tabular}{|l|c|c|c|c|c|c|c|c|c|c|c|}
\hline $\mathrm{C}_{i}^{\mathrm{N}}=\frac{\mathrm{N}_{i}}{\mathrm{~N}_{\text {lim }}}$ & 0 & 0.10 & 0.20 & 0.30 & 0.40 & 0.50 & 0.60 & 0.70 & 0.80 & 0.90 & 1.0 \\
\hline $\mathrm{C}_{i}^{\mathrm{U}}=\frac{\mathrm{U}_{i}}{\mathrm{U}_{\mathrm{lim}}}$ & 0 & 0.01 & 0.02 & 0.03 & 0.06 & 0.08 & 0.12 & 0.19 & 0.29 & 0.48 & 1.0 \\
\hline
\end{tabular}




$$
\begin{aligned}
& \mathrm{N}_{\mathrm{lim}}^{\text {prot }}=\mathrm{N}_{\mathrm{lim}}^{\mathrm{mod}} \cdot\left(\frac{\mathrm{L}^{\text {prot }}}{\mathrm{L}^{\mathrm{mod}}}\right) 2.6=0.20\left(\frac{320}{80}\right) 2.6=7.3 \mathrm{t} \\
& \mathrm{U}_{\mathrm{lim}}^{\text {prot }}=\mathrm{U}_{\mathrm{lim}}^{\text {mod }} \cdot \frac{\mathrm{U}^{\text {prot }}}{\mathrm{U}^{\text {mod }}}=0.30 \times 4=1.20 \mathrm{~cm}
\end{aligned}
$$

3. Compile the supposed diagram of «load-displacement» dependence for the prototype. For this purpose multiply maximum load and displacement values by the non-dimensional diagram coefficients from table I. The results are summarized in table 2 and the diagram $\mathrm{U}_{i}^{\text {prot }}=f\left(\mathrm{~N}_{i}^{\text {prot }}\right)$ is compiled (fig. 9 a, curve 1).

There are diagrams obtained experimentally and giving the opportunity to compare calculation results (fig. 9 a, curve 2). This very figure shows the comparative diagrams for other models of bored anchors (S 1.5: 10 curves $3.4 ; \mathrm{S} 2$; 10 - curves $5.6 ; \mathrm{S} 3$ : 10 - curves 7.8 ) in an identical soil.
Figure $9 \mathrm{~b}$ shows comparative diagrams for mushroom-like anchor $(a=b=110 \mathrm{~cm} ; h=1.5 \mathrm{~m}$ curves 1.2; $a=b=96 \mathrm{~cm}, h=131 \mathrm{~cm}$ - curves 3.4; $a=b=69 \mathrm{~cm} ; a=b=94 \mathrm{~cm}$ - curves 5.6; $a=b=55 \mathrm{~cm}, h=75 \mathrm{~cm}$ - curves 7.8$)$ in averagesized sand. Calculated (curve 1) and experimental curve 2) «load-displacement» dependence for cylindrical cross-bar anchor with the diameter of $56 \mathrm{~cm}$ and $300 \mathrm{~cm}$ long in morainic sandy loam with the pullout $=40^{\circ}$ are represented in fig. $9 \mathrm{c}$.

Calculated diagrams are obtained by the testing of models with a 1: 5 scale. Thus, the use of approximate values, while summarizing the results of approximate anchor foundation model testing, put in the first place the consideration of base soil properties and made it possible to solve a problem almost unsolvable for the practice of full identity and for analytical calculation methods.

TABLE 2

\begin{tabular}{|l|c|c|c|c|c|c|c|c|c|c|}
\hline $\mathrm{N}_{i}^{\text {prot }} t$ & 0.73 & 1.46 & 2.19 & 2.92 & 3.65 & 4.38 & 5.10 & 5.83 & 6.56 & 7.30 \\
\hline $\mathrm{U}_{i}^{\text {prot }} \mathrm{cm}$ & 0.01 & 0.02 & 0.04 & 0.07 & 0.10 & 0.14 & 0.23 & 0.34 & 0.58 & 1.20 \\
\hline
\end{tabular}

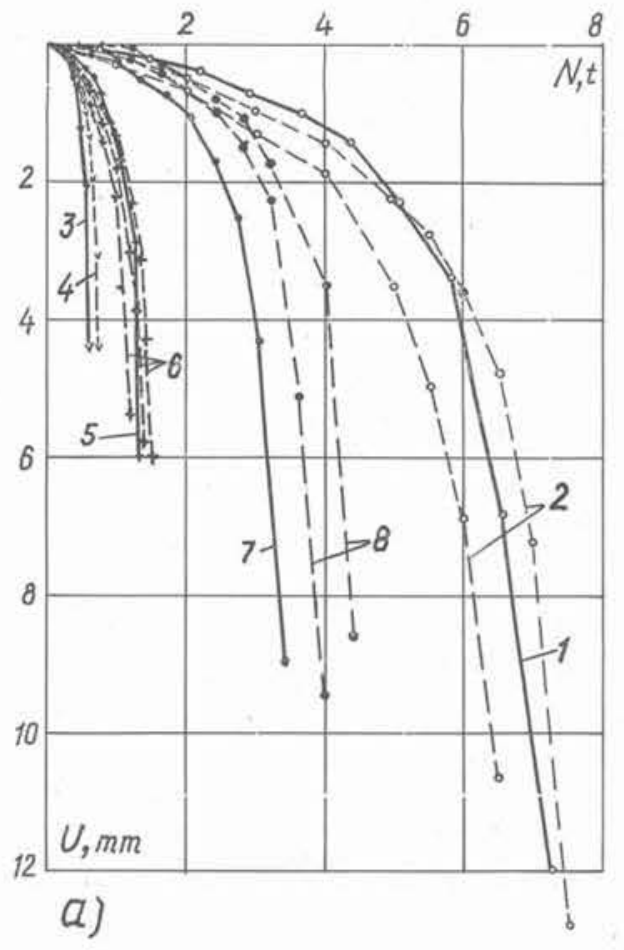

Fig. 9. - Analytical and experimental «load-displacement dependences:

a) for inclined bored anchor in soft sandy morainic loam;

b) for mushroom anchor foundations in sand;

c) for cross-bar cylindrical anchors in morainic sandy loam.
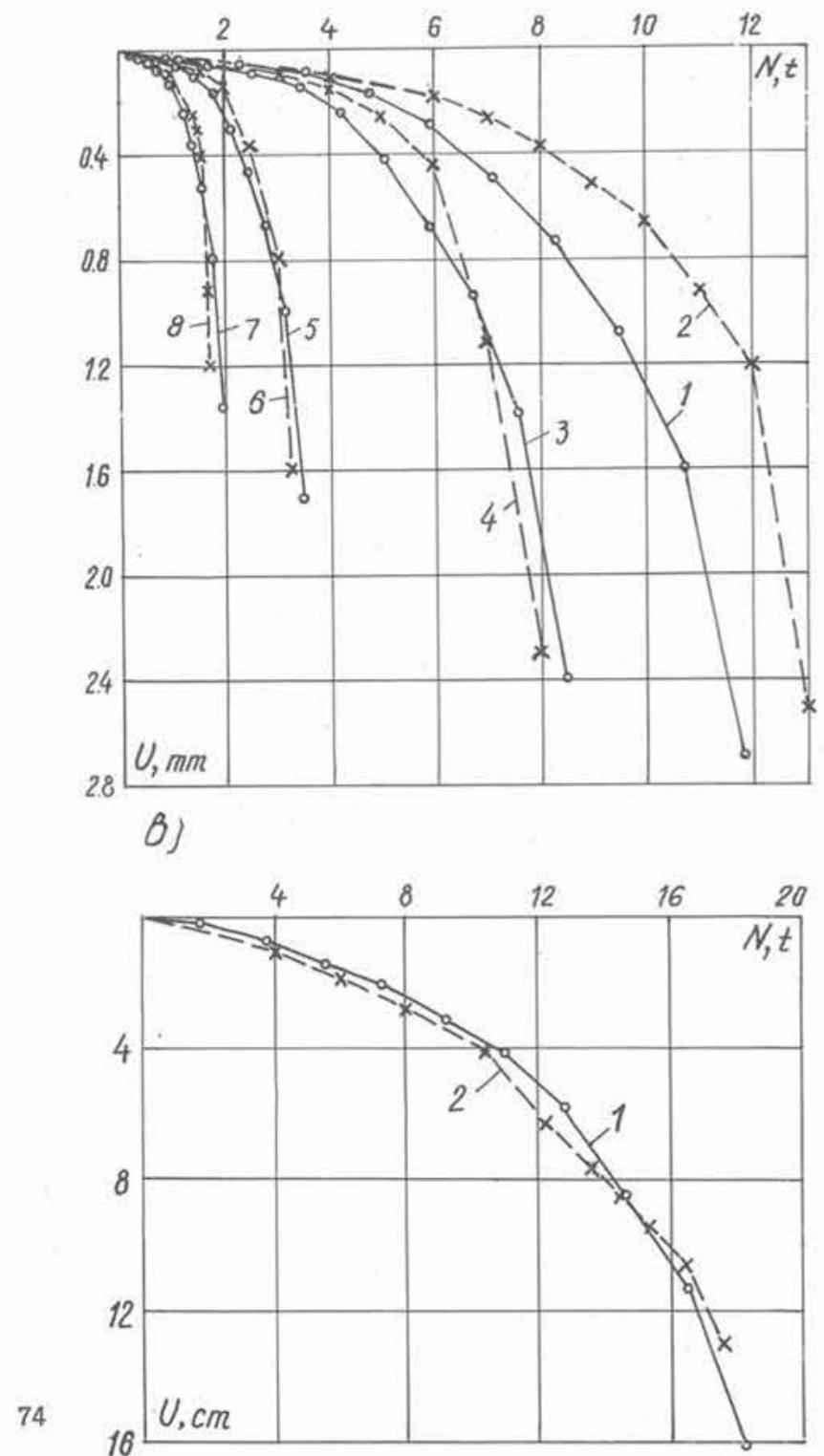


\section{REFERENCES}

[1] POLSHIN (D.E.), JHA (J.). - - On modelling of soil mechanics problem by V.I. Kurdjumov's method. NIIOSP Proceedings N 55, "Osnovanya e fundamenti», Stroyizdat, Moscow, (1964).

[2] CHIZHIKOV (P.G.). - Load-settlement dependencies between model and full size footings. Transportnoje stroitelstvo, No 6 (1967).

[3] JAROSHENKO (V.A.). - Modelling settlements of footings on sand foundations MIIT Proceedings, No 100 , "Mekhanika gruntov, osnovanya i fundamenti». Transzheldorizdat, Moscow (1959).

[4] KANANYAN (A.S.). - Experimental study of anchor foundations behavior, NIIOSP Proceedings, No 53, "Osnovanya e fundamenti», Moscow (1963).
[5] EKIMYAN (N.B.). - Generalized affinity technique and its application to piles, modelling. NIIOSP proceedings, No 65, "Svainye fundamenti», (1975).

[6] SOBOLEVSKY (Ju.A.). - Sukhodoev V.N. The study of cylindrical thrust anchors «Energiticheskoye stroitelstvo», No 12 (150), (1973).

[7] GABLIA (Ju.A.), NIKITENKO (M.I.), SHASHKO (S.D.). - The tests of new anchor modifications for securing bearing stays of overhead power transmission lines. «Energeticheskoye stroytelstvo», No 1 (187), pp. 73-76 (1977).

[8] KANANYAN (A.S.). - Experimental study of deformability and stability of anchor foundation bases. Proceedings of the Baltic conference on soil mechanics and foundation engineering, vol. 3, Gdansk, 22-25 (September 1975). 